\title{
Citrus Peels Phenolic Derivatives Alleviate Benzo[a]pyrene-Induced Inflammatory Injury of Human Intestinal Epithelial Cells Through NLRP3 and AhR Signaling Pathways
}

\author{
Zhuwei Liang \\ Shenzhen University \\ Huailing Wang \\ Shenzhen University \\ Dan Luo \\ Shenzhen University \\ Xiaoyu Liu \\ Shenzhen University \\ Jie Liu (DI5263882@126.com ) \\ Shenzhen University
}

\section{Original article}

Keywords: Citrus peels, Benzo[a]pyrene, Inflammation, NLRP3, AhR

Posted Date: November 12th, 2021

DOI: https://doi.org/10.21203/rs.3.rs-1031787/v1

License: (c) (i) This work is licensed under a Creative Commons Attribution 4.0 International License.

Read Full License 


\section{Abstract}

Benzo[a]pyrene (BaP) is ubiquitous in foods, and possesses a fatal cytotoxicity. In current study, ten Citrus peels (Chenpi) phenolic derivatives (CPDs) were isolated in a cell model of human intestinal epithelial (Caco-2) cells under BaP-exposure by a bio-assay guided method. Among them, methyl (3,4,5trimethoxybenzoyl) valylphenylalaninate (Citrus peels phenolic derivative-2, CPD-2) performed the most protective activity by promoting the antiinflammatory potential on BaP-induced Caco-2 cells. CPD-2 inhibited BaP-induced intracellular ROS over-production and inflammatory epithelial cytokine, IL-4, IL-8, TNF-a, IL-1 $\beta$ and IL-18 over-expression, but not IL-6. CPD-2 also inhibited BaP-induced NLRP3 inflammasome and AhR signaling pathway activation. Overall, CPD-2 attenuates BaP-induced apoptotic death via promoting the antiinflammatory potentials by inhibiting the NLRP3 and AhR signaling pathways activation of Caco-2 cells. Finally, the Citrus peels phenolic derivatives was observed for the first time against BaP-induced inflammation and oxidative stress in human intestinal epithelial cells.

\section{Introduction}

Polycyclic aromatic hydrocarbons (PAHs) are widespread environmental pollutants found in cigarette smoke, automobile exhaust and foods cooked at high temperature[1]. Benzo[a]pyrene (BaP) is a representative PAHs that has been suggested to cause human diseases, including cancers, cardiovascular, pulmonary and neurodegenerative diseases[2]. Currently, atherosclerosis is viewed as an inflammatory process driven, at least in part, by reactive oxygen species (ROS). BaP is known to generate superoxide and hydrogen peroxide via one-electron redox cycling of its metabolite, BaP-quinone[3].

Dried fruit peels of Citrus unshiu Markovich, $C$. reticulate Blanco, and $C$. tachibana Makino Tanaka, which are collectively known as "Chenpi", have been widely used as traditional medicine in Korea, China, and Japan[4]. In south China, Chenpi was infused by boiling water to extract their effective components and drunk just like tea, which is supposed to be beneficial to the health. One sort of the active biological constituents of Chenpi are adrenergic amines (such as synephrine, octopamine, and tyramine), at the same time, the hesperidin exists in Chenpi and is considered as the most functional compound $[5,6]$. Furthermore, the phenolics are also regarded as significant bio-active compounds and have been reported as anti-oxidative and anti-inflammatory agents in Chenpi[7, 8]. Of interest, the flavonoids in Chenpi, such as nobiletin and tangeretin, which also attracted significant interest for their properties of antiviral, antiinflammatory, and antiatherogenic activities $[9,10]$. Previous studies have also revealed that the flavonoids isolated from the Chenpi performed significant antiinflammatory activity both in vitro and in vivo[11]. However, very few studies of Chenpi phenolic derivatives (CPDs) have been documented for the effect against BaP-induced inflammatory injury in human intestinal epithelial cells. In current study, we designed experiments to reveal whether the CPDs can inhibit BaP-induced inflammatory damages in human intestinal epithelial cells.

\section{Materials And Methods}




\subsection{Materials and agents}

The "Chenpi" (dried fruit peels of Citrus unshiu Markovich) were acquired from the Jiangmen Palace international Food, inc (Guangdong, China), and was authenticated by professor Guangxiong Zhou, College of Pharmacy, Jinan University. A voucher specimen was deposited in the Herbarium of the College of Pharmacy, Jinan University. PierceTM BCA Protein Assay Kit was obtained from Thermo Fisher Scientific (Rockford, IL, USA). CCK8 assay kit and RIPA buffer were purchased from Beyotime (Shanghai, China). Penicillin-streptomycin (Pen Strep), fetal bovine serum (FBS) were purchased from Gibco (Grand Island, NY, USA). The antibodies were purchased from Cell Signaling Technology (CST, Beverly, MA, USA). The other chemicals used in the current study were purchased from Aldrich or Adamas without any further purification.

\subsection{General apparatus and isolation of CPDs}

The preparative high performance liquid chromatography (HPLC) was performed on a Varian Postar 210 chromatograph equipped with a Varian-306 pump and a Varian UV/vis-152 detector with a C18 reversedphase column (Cosmosil, $10 \mathrm{~mm} \times 250 \mathrm{~mm}, 5 \mu \mathrm{m}$ ). ESI-MS data were detected on a Finnigan LCQ Advantage Max ion trap mass spectrometer. NMR spectra were detected on Bruker Avance 400 or 500 $\mathrm{MHz}$ spectrometer. The chemical shifts were expressed in $\delta$ value (ppm). Silica gel (300-400 mesh, Qingdao Marine Chemical Inc., China) was used for column chromatography. All the other reagents were acquired from Guangzhou Jierui Chemical Company (Guangzhou, China).

A modified method was used to isolated the extract of Chenpi in current study[12]. After that, the Chenpi extract $(113 \mathrm{~g})$ passed through a silica gel column chromatography $(5 \mathrm{~cm} \times 90 \mathrm{~cm}, 200$ mesh, $500 \mathrm{~g})$ eluted with chloroform and methanol gradients (100:5, 100:20, 100:50, 100:100 and 10:100, v/v) and to obtain 5 fractions (Fra-A E). Then, the protective activity against BaP induced Caco-2 cell viability decrease was detected. The Fraction performed the most protective activity was subjected to further isolation. Fra-C $(22.9 \mathrm{~g})$ was further purified by silica gel column chromatography $(5 \mathrm{~cm} \times 90 \mathrm{~cm}, 400$ mesh, $400 \mathrm{~g}$ ) eluted with ethyl acetate-methanol gradients (100:5, 100:20, 100:50, 100:100 and 10:100, $\mathrm{v} / \mathrm{v}$ ) and to obtain 5 fractions (Fra-C-1 5). Then, the protective activity against BaP induced Caco-2 cell viability decrease was detected. The Fraction performed the most protective activity was subjected to further isolation. CPD-1 (6.59 mg), 3 (7.74 mg), 6 (10.1 mg), 8 (7.59 mg) and 10 (9.33 mg) were isolated by a silica gel column $(5 \mathrm{~cm} \times 50 \mathrm{~cm}, 400$ mesh, $120 \mathrm{~g})$ eluted with ethyl acetate-methanol $(100: 10 \mathrm{v} / \mathrm{v})$ from Fra-C-3. CPD-2 (11.3 mg) 4 (7.18 mg), 5 (8.24 mg), 7 (3.55 mg) and 9 (8.20 mg) were isolated by a silica gel column $(5 \mathrm{~cm} \times 50 \mathrm{~cm}, 400$ mesh, $120 \mathrm{~g})$ eluted with ethyl acetate-methanol $(100: 50 \mathrm{v} / \mathrm{v})$ from Fra-C-4.

\subsection{Cell culture and cell counting kit-8 assay}

Caco-2 cells were cultured in DMEM high glucose with stable L-glutamine, supplemented with $10 \%$ FBS, $100 \mathrm{U} / \mathrm{mL}$ penicillin, $100 \mu \mathrm{g} / \mathrm{mL}$ streptomycin with incubation at $37^{\circ} \mathrm{C}$ under $5 \% \mathrm{CO}_{2}$ atmosphere. 
The cell viability of the Caco-2 cells was evaluated using cell counting kit-8 (CCK-8) (Beyotime Biotech.) as reported previously[13], following the manufacturer's protocols. The Caco- 2 cells $\left(1 \times 10^{4}\right.$ cells $\left./ \mathrm{mL}\right)$ were seeded in 96-well plates for $12 \mathrm{~h}$. Then, the Caco-2 cells were treated with $1.0 \mu \mathrm{mol} / \mathrm{L} \mathrm{BaP}$ or PBS. After incubation for $12 \mathrm{~h}$, the Caco- 2 cells were collected and washed with cold PBS for twice. Then, the HUCECs were treated with the samples or PBS for $24 \mathrm{~h}$. Afterwards, the CCK-8 reagent was added to each

well at $10 \mu \mathrm{L} / \mathrm{mL}$ final concentration and incubated at $37^{\circ} \mathrm{C}$ for another $4 \mathrm{~h}$. Finally, cell viability of Caco-2 cells was determined with a microplate reader (Bio-Rad).

\subsection{Cell Apoptosis Assay}

Caco- 2 cells $\left(2 \times 10^{5} /\right.$ well $)$ were plated in 6-well plate. The Caco-2 cells were incubated with $1.0 \mu \mathrm{mol} / \mathrm{L}$ $\mathrm{BaP}$ or PBS for additional $12 \mathrm{~h}$, then, Caco-2 cells were collected and washed with cold PBS. After that, the Caco-2 cells were treated with the CPD-2 (10 or $100 \mu \mathrm{mol} / \mathrm{L}$ ) or PBS for $24 \mathrm{~h}$. Afterwards, the Caco-2 cells were collected, washed with cold PBS, suspended in binding buffer $(100 \mu \mathrm{L})$ (BD Biosciences, CA, USA), treated with Annexin $\mathrm{V}$ and Propidium iodide (PI), and incubated in dark for 15 min, anther $300 \mu \mathrm{L}$ binding buffer was added, then flow cytometry analysis was performed within $1 \mathrm{~h}$ to measure the apoptosis rate (\%).

\subsection{Intracellular ROS and Epithelial Cytokines Assays}

Intracellular reactive oxygen species were quantified with Reactive Oxygen Species Assay Kit (Beyotime Institute of Biotechnology) as previously described. Briefly, Caco-2 cells $\left(2 \times 10^{5} /\right.$ well) were plated in 6well plate. The Caco-2 cells were incubated with $1.0 \mu \mathrm{mol} / \mathrm{L} \mathrm{BaP}$ or PBS for additional $12 \mathrm{~h}$, then, Caco-2 cells were collected and washed with cold PBS. After that, the Caco-2 cells were treated with the CPD-2 (10 or $100 \mu \mathrm{mol} / \mathrm{L}$ ) or PBS for $24 \mathrm{~h}$. After that, the Caco-2 cells were collected, and washed triple with serum free medium. Then, the Caco- 2 cells were incubated in $200 \mu \mathrm{L}$ of serum free medium containing DCFH-DA $(25 \mu \mathrm{M})$ for $30 \mathrm{~min}$ at room temperature. The DCF fluorescence was quantitated with a Multiskan Go plate reader (Thermo), with an excitation wavelength of $488 \mathrm{~nm}$ and an emission wavelength of $525 \mathrm{~nm}$, and normalized with the total protein content.

After treatments with BaP or CPD-2, the cell supernatant was collected, and the concentration of interleukin-6 (IL-6), interleukin-8 (IL-8), interleukin-1 $\beta$ (IL-1 $\beta$ ), TNF-a, and IL-18, was quantified by using commercial quantikine ELISA kit according to the manufacturer's instructions. All the experiments were performed at least three times.

\subsection{Western blotting}

Caco-2 cells $\left(2 \times 10^{5} /\right.$ well $)$ were plated in 6 -well plate. The Caco-2 cells were incubated with $1.0 \mu \mathrm{mol} / \mathrm{L}$ $\mathrm{BaP}$ or PBS for additional $12 \mathrm{~h}$, then, Caco-2 cells were collected and washed with cold PBS. After that, the Caco-2 cells were treated with the CPD-2 (10 or $100 \mu \mathrm{mol} / \mathrm{L}$ ) or PBS for $24 \mathrm{~h}$. After that, the Caco-2 cells were collected, washed with cold PBS, the total cellular proteins were collected after lysed in RIPA buffer and the protein concentrations were measured with BCA protein assay kit. The western blot 
analysis was carried out with the method reported previously[14]. The $\beta$-actin or GAPDH were used as internal standard of process control. Blot bands densitometry was analyzed with Image $J$ software.

\subsection{Statistical analysis}

Data were analyzed using one-way analysis of variance (ANOVA). Tukey's multiple comparison test was used to detect differences between means, and statistical signifificance was set at $p<0.05$. All statistical analyses were performed using SPSS software 21.0 (SPSS Inc., Chicago, IL, USA). Graphs were generated using INSTAT software (GraphPad Software, San Diego, CA, USA).

\section{Results}

\subsection{Isolation and structure identification of CPDs}

Eventually, five novel Citrus peels (Chenpi) phenolic derivatives (CPDs) were isolated in a cell model of human intestinal epithelial (Caco-2) cells under BaP-exposure by a bio-assay guided method, named (3,4,5-trimethoxybenzoyl)valylphenylalanine (CPD-1), methyl (3,4,5-

trimethoxybenzoyl)valylphenylalaninate (CPD-2), methyl (3,4,5-trimethoxybenzoyl)valylprolinate (CPD-3), methyl (3,4,5-trimethoxybenzoyl)valylvalinate (CPD-4), methyl 3-methyl-2-(3-methyl-2-(3,4,5trimethoxybenzamido)butanamido)pentanoate (CPD-5). Furthermore, five known CPDs were also isolated and structure identified, named 1-(2,4-dihydroxy-6-methoxy-5-(1-methoxy-3-methylbutyl)-3-(3-methylbut-2en-1-yl)phenyl)ethan-1-one (CPD-6), 1-(3-acetyl-2,6-dihydroxy-4-methoxy-5-(3-methylbut-2-en-1yl)phenyl)-3-methylbutan-2-one (CPD-7), 1-(2,4-dihydroxy-6-methoxy-3-(3-methylbut-2-en-1yl)phenyl)ethan-1-one (CPD-8), 2-butyryl-6-(3-butyryl-2,4-dihydroxy-6-methoxybenzyl)-3,5-dihydroxy-4,4dimethylcyclohexa-2,5-dien-1-one (CPD-9), 2-acetyl-6-(3-butyryl-2,4-dihydroxy-6-methoxybenzyl)-3,5dihydroxy-4,4-dimethylcyclohexa-2,5-dien-1-one (CPD-10). Their structures (Figure 1) were identified by ${ }^{1} \mathrm{H}-\mathrm{NMR},{ }^{13} \mathrm{C}$-NMR, and ESI-MS analyses. The ${ }^{1} \mathrm{H}-\mathrm{NMR},{ }^{13} \mathrm{C}-\mathrm{NMR}$, and ESI-MS data of CPD-1 5 were list as follows:

CPD-1: White powder, ${ }^{1} \mathrm{H}$ NMR (500 MHz, DMSO) $\delta: 0.68\left(\mathrm{~m}, 6 \mathrm{H}, 2-\mathrm{CH}_{3}\right), 2.89(\mathrm{~m}, 1 \mathrm{H},-\mathrm{CH}), 3.07(\mathrm{~m}, 2 \mathrm{H},-$ $\left.\mathrm{CH}_{2}-\right), 3.71\left(\mathrm{~s}, 3 \mathrm{H},-\mathrm{OCH}_{3}\right), 3.83\left(\mathrm{~s}, 6 \mathrm{H}, 2-\mathrm{OCH}_{3}\right), 4.31(\mathrm{~m}, 1 \mathrm{H},-\mathrm{CH}-), 4.42(\mathrm{~m}, 1 \mathrm{H},-\mathrm{CH}-), 7.19(\mathrm{~m}, 7 \mathrm{H},-\mathrm{CH}-)$, 8.30 (m, 2H, 2-NH-); ${ }^{13} \mathrm{C}$ NMR (125 MHz, DMSO) $\delta:{ }^{13} \mathrm{C}$ NMR (125 MHz, DMSO) $\delta 172.94,172.75,171.10$, $152.48,152.47,139.99,137.55,129.54,129.18,129.14$, 128.09, 128.04, 126.33, 105.17, 60.09, 58.97, $57.79,56.07,53.46,30.18,19.29,18.98$. ESI-MS: $m / z 483.1[\mathrm{M}+\mathrm{Na}]^{+}, \mathrm{C}_{24} \mathrm{H}_{30} \mathrm{~N}_{2} \mathrm{O}_{7}$.

CPD-2: White powder, ${ }^{1} \mathrm{H}$ NMR (600 MHz, DMSO) $\delta: 0.69\left(\mathrm{~m}, 3 \mathrm{H},-\mathrm{CH}_{3}\right), 0.90\left(\mathrm{~m}, 3 \mathrm{H},-\mathrm{CH}_{3}\right), 3.04(\mathrm{~m}, 2 \mathrm{H},-$ $\left.\mathrm{CH}_{2}-\right), 3.55\left(\mathrm{~s}, 3 \mathrm{H},-\mathrm{OCH}_{3}\right), 3.70\left(\mathrm{~s}, 3 \mathrm{H},-\mathrm{OCH}_{3}\right), 3.83\left(\mathrm{~s}, 6 \mathrm{H}, 2-\mathrm{OCH}_{3}\right), 4.35(\mathrm{~m}, 1 \mathrm{H},-\mathrm{CH}-), 4.48(\mathrm{~m}, 1 \mathrm{H},-\mathrm{CH}-)$, 7.21 (m, 7H, 7-CH-), 8.18 (dd, 1H, -NH-), 8.51 (t, 1H, -NH-); ${ }^{13} \mathrm{C}$ NMR (150 MHz, DMSO) $\delta: 171.78,171.14$, $165.60,152.49$, 152.47, 140.07, 140.02, 137.17, 137.08, 129.15, 129.07, 128.19, 128.15, 126.50, 126.48, $105.16,105.15,60.10,58.68,56.07,56.05,53.51,51.71,36.58,30.34,18.94,18.58$. ESI-MS: $m / z 473.1$ $[\mathrm{M}+\mathrm{H}]^{+}, 495.0[\mathrm{M}+\mathrm{Na}]^{+}, \mathrm{C}_{25} \mathrm{H}_{32} \mathrm{~N}_{2} \mathrm{O}_{7}$. 
CPD-3: White powder, ${ }^{1} \mathrm{H}$ NMR (600 MHz, DMSO) $\delta: 0.86\left(\mathrm{~m}, 3 \mathrm{H},-\mathrm{CH}_{3}\right), 0.91\left(\mathrm{~m}, 3 \mathrm{H},-\mathrm{CH}_{3}\right), 1.92(\mathrm{~m}, 3 \mathrm{H},-$ $\left.\mathrm{CH}_{3}\right), 2.16(\mathrm{~m}, 2 \mathrm{H}, 2-\mathrm{CH}), 3.41\left(\mathrm{~m}, 2 \mathrm{H},-\mathrm{CH}_{2}-\right), 3.58\left(\mathrm{~s}, 3 \mathrm{H},-\mathrm{OCH}_{3}\right), 3.71\left(\mathrm{~s}, 3 \mathrm{H},-\mathrm{OCH}_{3}\right), 3.82\left(\mathrm{~s}, 3 \mathrm{H},-\mathrm{OCH}_{3}\right)$, $4.31(\mathrm{~m}, 1 \mathrm{H},-\mathrm{CH}-), 4.58(\mathrm{~m}, 1 \mathrm{H},-\mathrm{CH}-), 7.28(\mathrm{~m}, 2 \mathrm{H}, 2-\mathrm{CH}-), 8.54(\mathrm{~d}, 1 \mathrm{H},-\mathrm{NH}-) ;{ }^{13} \mathrm{C}$ NMR $(150 \mathrm{MHz}, \mathrm{DMSO}) \delta$ : 172.26, 169.94, 152.52, 140.08, 128.98, 105.22, 60.08, 58.37, 56.05, 51.65, 46.87, 29.65, 28.68, 24.34, 19.16, 18.89. ESI-MS: $m / z 423.7[\mathrm{M}+\mathrm{H}]^{+}, \mathrm{C}_{21} \mathrm{H}_{30} \mathrm{~N}_{2} \mathrm{O}_{7}$.

CPD-4: White powder, ${ }^{1} \mathrm{H}$ NMR (600 MHz, DMSO) $\delta: 0.92\left(\mathrm{~m}, 12 \mathrm{H}, 4-\mathrm{CH}_{3}\right), 2.06(\mathrm{~m}, 1 \mathrm{H},-\mathrm{CH}-), 2.13(\mathrm{~m}, 1 \mathrm{H},-$ $\mathrm{CH}-)$, $3.60\left(\mathrm{~s}, 3 \mathrm{H},-\mathrm{OCH}_{3}\right), 3.69\left(\mathrm{~s}, 3 \mathrm{H},-\mathrm{OCH}_{3}\right), 3.84\left(\mathrm{~s}, 6 \mathrm{H}, 2-\mathrm{OCH}_{3}\right), 4.14(\mathrm{dt}, 1 \mathrm{H},-\mathrm{CH}-), 4.41(\mathrm{dt}, 1 \mathrm{H},-\mathrm{CH}-)$, 7.21 (m, 2H, 2-CH-), 8.34 (dd, 2H, 2-NH-); ${ }^{13} \mathrm{C}$ NMR (150 MHz, DMSO) $\delta: 171.84,171.63,165.80,152.51$, $140.03,129.50,105.17,60.10,58.86,57.65,56.09,51.69,30.50,29.87,19.35,19.07,18.91,18.34$. ESI-MS: $\mathrm{m} / \mathrm{z} 447.1[\mathrm{M}+\mathrm{Na}]^{+}, \mathrm{C}_{21} \mathrm{H}_{32} \mathrm{~N}_{2} \mathrm{O}_{7}$.

CPD-5: White powder, ${ }^{1} \mathrm{H}$ NMR (600 MHz, DMSO) $\delta: 0.92\left(\mathrm{~m}, 12 \mathrm{H}, 4-\mathrm{CH}_{3}\right), 1.38\left(\mathrm{~m}, 2 \mathrm{H},-\mathrm{CH}_{2}-\right), 1.81(\mathrm{~m}, 1 \mathrm{H}$, $-\mathrm{CH}-), 2.11(\mathrm{~m}, 1 \mathrm{H},-\mathrm{CH}-), 3.61\left(\mathrm{~s}, 3 \mathrm{H},-\mathrm{OCH}_{3}\right), 3.69\left(\mathrm{~s}, 3 \mathrm{H},-\mathrm{OCH}_{3}\right), 3.84\left(\mathrm{~s}, 6 \mathrm{H},-\mathrm{OCH}_{3}\right), 4.17(\mathrm{dt}, 1 \mathrm{H},-\mathrm{CH}-)$, 4.41 (dt, $1 \mathrm{H},-\mathrm{CH}-), 7.21$ (m, 2H, 2-CH-), 8.28 (dd, 2H, 2-NH-); ${ }^{13} \mathrm{C}$ NMR (150 MHz, DMSO) $\delta: 171.79,171.43$, $165.75,152.51,140.02,129.50,105.11,60.08,58.64,56.57,56.05,51.65,36.27,30.55,24.91,19.30$, 18.80, 11.19, 10.94. ESI-MS: $m / z 439.2[\mathrm{M}+\mathrm{H}]^{+}, 461.2[\mathrm{M}+\mathrm{Na}]^{+}, \mathrm{C}_{22} \mathrm{H}_{34} \mathrm{~N}_{2} \mathrm{O}_{7}$.

After the ten CPDs were isolated, the cytotoxicity in Caco-2 cells was first evaluated ( 24,48 and $72 \mathrm{~h}$ ). The results showed that all the CPDs performed no cytotoxicity in Caco-2 cells up to $1.0 \mathrm{mM}(72 \mathrm{~h})$.

We then detected the protective activity of the CPDs against BaP-induced Caco- 2 cells cell viability decline, and the results were list in Table 1 . The BaP-exposure significantly decreased the cell viability. When compared to the control group, the BaP-exposure decreased the cell viability by $18.4 \%(p<0.05)$, which indicated that the BaP-exposure induced fatal damages to the Caco-2 cells. Interestingly, BaPexposure induced cell viability decrease was attenuated by most of the CPDs. Among them, the CPD-1, CPD-2 and CPD-3 displayed better protective activity than the resveratrol (positive control). Furthermore, the CPD-2 mostly promoted the viability of Caco-2 cells. 
Table 1

CPDs inhibit BaP-induced Caco-2 cell viability decline

\begin{tabular}{|c|c|}
\hline Group & Cell viability ( $100 \%$ Control) \\
\hline Control & $100 \pm 4.42$ \\
\hline $\mathrm{BaP}$ & $81.6 \pm 3.55^{\# \#}$ \\
\hline CPD-1 & $93.2 \pm 3.20^{*}$ \\
\hline CPD-2 & $95.7 \pm 3.03^{\star *}$ \\
\hline CPD-3 & $89.5 \pm 3.26^{*}$ \\
\hline CPD-4 & $86.1 \pm 3.10$ \\
\hline CPD-5 & $84.4 \pm 3.23$ \\
\hline CPD-6 & $85.4 \pm 2.98$ \\
\hline CPD-7 & $86.3 \pm 3.12$ \\
\hline CPD-8 & $84.2 \pm 3.08$ \\
\hline CPD-9 & $88.4 \pm 3.13$ \\
\hline CPD-10 & $88.3 \pm 3.25$ \\
\hline Resveratrol & $89.8 \pm 3.17^{\star}$ \\
\hline \multicolumn{2}{|c|}{$\begin{array}{l}\text { The Caco- } 2 \text { cells }\left(1 \times 10^{4} \text { cells } / \mathrm{mL}\right) \text { were seeded in } 96 \text {-well plates for } 12 \mathrm{~h} \text {. Then, the Caco- } 2 \text { cells were } \\
\text { treated with } 1.0 \mu \mathrm{mol} / \mathrm{L} \text { BaP or PBS. After incubation for } 12 \mathrm{~h} \text {, the Caco- } 2 \text { cells were collected and } \\
\text { washed with cold PBS for twice. Then, the Caco- } 2 \text { cells were treated with the CPDs }(10 \mu \mathrm{mol} / \mathrm{L}) \text { or } \\
\text { PBS for } 24 \mathrm{~h} \text {. Afterwards, the CCK- } 8 \text { reagent was added to each well at } 10 \mu \mathrm{L} / \mathrm{mL} \text { final concentration } \\
\text { and incubated at } 37^{\circ} \mathrm{C} \text { for another } 4 \text { h. Finally, cell viability of Caco-2 cells was determined with a } \\
\text { microplate reader (Bio-Rad). Data represent means } \pm \text { standard deviations }(\mathrm{SD}) \text { for three independent } \\
\text { experiments. }\left(\mathrm{n}=3,{ }^{* *} p<0.01,{ }^{*} p<0.05 \text {, compared to the BaP group; }{ }^{*} p<0.05 \text {, \#\# } p<0.01 \text {, compared to }\right. \\
\text { the Control group). }\end{array}$} \\
\hline
\end{tabular}

In current study, cytotoxicity of CPD-2 in Caco-2 cells was further explored. The results indicated that CPD-2 did not exhibit cycotoxicity up to $1.25 \mathrm{mM}$ (72 h, Figure 2A). Furthermore, CPD-2 performed the protective activity against BaP-exposure induced cell viability decrease in a time- and dose-dependent manner (Figure 2B, 2C).

\subsection{Effect of CPD-2 on BaP-induced oxidative stress and inflammation in Caco- 2 cells}

The oxidative stress triggered by BaP induced the increase of ROS production in vitro[15]. As shown in Figure 2D, compared to the control group, BaP-exposure increased the intracellular ROS level by $970.7 \%$ ( $p$ $<0.01$ ), which indicated that BaP-exposure caused fatal oxidative stress in Caco-2 cells. Remarkably, the 
BaP-induced ROS over-production was attenuated after the CPD-2 treatments. Compared to the BaP group, CPD-2 decreased the intracellular ROS level by $72.8 \%(p<0.05)$ and $81.7 \%(p<0.01)$, respectively.

PAHs adversely affect human immune functions by inducing the expression of inflammatory cytokines, thereby enhancing the atherosclerosis[16]. In the current study, we detected whether the CPD-2 performed the protective effect was through inhibiting the expression of the inflammatory epithelial cytokines (IL-6, IL-8, IL-1 $\beta$, IL-4, TNF- $\alpha$, and IL-18) in BaP-induced Caco-2 cells. Compared to the control group, the BaPinduced inflammatory epithelial cytokine levels of IL-6, IL-8, IL-1 $\beta$, IL-4, TNF- $a$, and IL-18 increased by $248.7 \%(p<0.01), 283.1 \%(p<0.01), 202.5 \%$ ( $p<0.01), 477.6 \%(p<0.01), 77.3 \%(p<0.01)$ and $478.4 \%$ $(p<0.01)$, which indicated that the Caco-2 cells were suffered fatal inflammatory damages. However, the BaP-induced inflammatory epithelial cytokine over-release was attenuated by the CPD-2 significantly. compared to the BaP group, the IL-8, IL-1 $\beta$, IL-4, TNF- $a$, and IL-18 levels were decreased by $56.1 \%(p<0.01)$, $50.7 \%(p<0.01), 66.4 \%(p<0.01), 36.7 \%(p<0.05)$ and 62.2\% ( $p<0.01)$, respectively, after the $100 \mu \mathrm{M}$ CPD-2 treatments, but no change was noted for IL-6 (Figure 2E). Definitely, the CPD-2 inhibited BaP-induced inflammatory epithelial cytokine over-expression of Caco-2 cells.

\subsection{Effect of CPD-2 on BaP-induced Caco-2 cells apoptosis}

Apoptosis plays a pivotal role in promoting resolution of the acute inflammatory response[17]. The BaPinduced oxidative stress and inflammatory damages can subsequently result in the cell apoptosis[18]. Hence, we detected whether the CPD-2 can attenuate the BaP-induced Caco-2 cell apoptosis, and the results were list in Figure 3A. The BaP-exposure induced 23.1\% total apoptosis/necrosis, where $16.1 \%$ early apoptosis and $4.34 \%$ late apoptosis, and the early apoptosis performed a significant contribution. The cell apoptosis provided a visually evidence that the Caco-2 cells suffered fatal injury after the BaPexposure. However, the BaP-induced cell apoptosis was inhibited by the CPD-2 treatment. Compared to the BaP group, the CPD-2 decreased the total apoptosis \& necrosis by $3.80 \%, 6.70 \%(p<0.05)$, respectively. Cell apoptosis provided visually evidence for the protective effect of CPD-2 against the BaPinduced Caco-2 cells apoptosis.

The cellular oxidative stress caused by the ROS over-production, can be part of signal transduction pathway during cell apoptosis. Bcl-2 is identified to have anti-apoptotic potential in a variety of cell systems[19]. Bcl-2 maintains the membrane integrity of mitochondria, by directly or indirectly preventing the release of cytochrome $C$, which, along with apoptotic protease-activating factor-1 (APAF-1)[20]. In the present study, we also evaluated whether the Bcl-2 involved in the protective effect of CPD-2 against the BaP-induced Caco-2 cells apoptosis. As shown in Figure 3B, BaP-exposure induced the release of cytochrome $\mathrm{C}$, and induced the over-expression of APAF-1 and Bax, respectively. At the same time, BaPexposure inhibited the expression of $\mathrm{Bcl}-2$ of $\mathrm{Caco}-2$ cells. Intriguingly, the $\mathrm{BaP}$-induced cytochrome $\mathrm{C}$ release, and APAF-1 over-expression were significantly suppressed by the CPD-2 treatments. At the same time, the BaP-induced up-regulation of Bax/Bcl-2 ratio was also reversed by the CPD-2 treatments.

\subsection{Effects of CPD-2 on BaP-induced NLRP3 inflammasome activation}


The NOD-like receptor superfamily, pyrin domain containing 3 (NLRP3) inflammasome is composed of NLRP3, apoptosis-associated speck-like protein (ASC) and caspase-1. Caspase-1 is a component of inflammasome with NOD like receptors (NLRs) and their adaptor proteins, and is activated within inflammasome in response to various stressor molecules[21]. The NLRP3 interacts with ASC to activate caspase-1, subsequently leads to maturation and secretion of inflammatory cytokines interleukin (IL)-1 $\beta$ and IL-18, which are involved inflammation response[22, 23].

In current study, the BaP-induced inflammation was characterized by the up-regulated levels of inflammatory epithelial cytokines in Caco-2 cells, which were attenuated by the treatments of CPD-2. We evaluated the expression of NLRP3, ASC and caspase-1, to conform that the NLRP3 inflammasome inhibition was also involved in CPD-2 protection against the BaP-induced inflammation in Caco-2 cells. As shown in Figure 4A, the expressions of Caspase-1, ASC and NLRP3 were significantly increased. However, the BaP-exposure-induced NLRP3 inflammasome activation was significantly inhibited by the CPD-2 treatments. The western blotting results indicated that the NLRP3 inflammasome was involved in the protective effect of CPD-2.

\subsection{Effects of CPD-2 on BaP-induced AhR signal activation}

Free radicals are injurious to cellular lipids, proteins, and nuclear or mitochondrial DNA, inhibiting their normal function, as well as interfering with the signaling pathways within cells. A common cellular mechanism by which $\mathrm{BaP}$ exerts adverse effects is its propensity to act directly as free radical generators, promoting oxidative stress and the induction of inflammatory responses. Human cytochrome P450 (CYP450) enzymes are primarily membrane-associated proteins located either in the inner membrane of the mitochondria or the endoplasmic reticulum of cells. CYP1A1 and CYP1B1 are the most important human P450 enzymes involved in the metabolic activation of PAHs[24]. For example, BaP is transformed in vivo to BP-7,8-epoxide by CYP1A1 through the CYP/EH pathway[25]. Aryl hydrocarbon receptor (AhR) is a ligand-activated transcription factor that is activated by small molecules provided by the diet, microorganisms, and pollutants. Upon ligand binding, AhR translocates from cytosol to the nucleus, leading to changes in target gene transcription (eg, cytochrome P450 cyp1a1, cyp1b1) and immunotoxicological effects. AhR activation has been shown to be critical in mediating BaP-induced oxidative stress and inflammation[26, 27].

To determine whether AhR signaling can also be inhibited by CPD-2 and plays a role in mediating BaPinduced up-regulation of inflammatory epithelial cytokines expression, the transcription of AhR and its major downstream gene cyp1a1 was assessed. As expected, BaP induced significantly increased $A h R$ transcription. Similar results were observed for cyp1a1 (Figure 4B). The BaP-induced expression of AhR and CYP1A1 was attenuated by the CDP-2 treatment was further confirmed by the western blotting (Figure 4C). Definitely, BaP-induced AhR signaling activation was blocked by the CPD-2 treatments.

To determine whether AhR is involved in BaP-induced inflammatory epithelial cytokines expression, AhR in Caco-2 cells was knocked down by siRNA, and then the cells were exposed to the BaP, and confirmed 
by western blotting (Figure 5D). Expression of inflammatory epithelial cytokines was analyzed by ELISA as reported previously[27].

As expected, AhR knockdown significantly blocked the BaP-induced inflammatory epithelial cytokines expression as detected by the ELISA, but no change was noted for IL-6 (Figure 5E). These results imply that the AhR signal pathway plays pivotal role of CPD-2 inhibiting BaP-induced over-release of inflammatory epithelial cytokines in Caco-2 cells.

\section{Discussion}

In south China, Chenpi was infused by boiling water to extract their effective components and drunk just like tea, which is supposed to be beneficial to the health. The Chenpi hesperidin is considered as the most functional compound[5, 6]. Furthermore, the flavonoids in Chenpi, such as nobiletin and tangeretin, which also attracted significant interest for their bio-active effects $[9,10]$. Cardiovascular disease is the leading cause of death globally. Studies elucidated that vascular inflammation, oxidative stress and endothelial dysfunction are pivotal risk factors involved in atherosclerosis[28]. Benzo[a]pyrene $(\mathrm{BaP})$ is one of the main ingredients in cigarettes and barbecue food. As reported, $\mathrm{BaP}$ is usually oxidized, which can induce inflammation and oxidative stress[29]. In current study, human intestinal epithelial cells were stimulated with $\mathrm{BaP}$ to establish an inflammatory and oxidative stress cell model. After the bio-active compounds were isolated in an activity tracking method in the cell model of Caco-2 cells under BaP-exposure from the Citrus peels (Chenpi) extract, the potential molecular mechanisms were further explored.

The endothelial cells play a crucial role in keeping cardiovascular homeostasis and usually work as the first defensive line in vessels. Endothelial dysfunction in vessels usually is due to the combined effect of oxidative stress and inflammation[30]. In current study, the BaP-exposure attenuated the viability of Caco2 cells, while the CPDs treatment reversed its effect, suggesting CPDs may have potential effect against the BaP-induced Caco-2 cells damages.

Endothelial senescence also leads to the specialized cell apoptosis, inflammation and oxidative stress contributing to age-associated diseases, including atherosclerosis[31]. Previous studies demonstrated that the cytotoxic drugs stimulates the NLR protein (NLRP3) inflammasome through the M2 protein, and that caspase-1 and apoptosis-associated speck-like protein containing a carboxy-terminal caspase activation and recruitment domain (ASC) is required. Study has also indicated that BaP induces the inflammasome, leading to the activation of caspase- 1 and the production of inflammatory epithelial cytokines[32]. In the present study, the treatment of CPD-2 suppressed the apoptosis of Caco-2 cells induced by BaP-exposure. Furthermore, the BaP-exposure caused an increase expression of NLRP3, ASC and caspase-1, which can aggravate severity of inflammation in Caco-2 cells. Interestingly, CPD-2 suppressed the expression of NLRP3, ASC and caspase- 1 of Caco-2 cells under BaP-exposure. These data suggested CPD-2 may ameliorate the BaP-induced endothelial inflammation by inhibiting the NLRP3 inflammasome activation. 
The release of cytochrome $\mathrm{C}$ from mitochondria has been shown as another important effector molecule in the mediation of apoptosis[20]. The Bcl-2 maintains the membrane integrity of mitochondria, by directly or indirectly preventing the release of cytochrome $\mathrm{C}$, which, along with APAF-1. Bcl-2 protects cells against diverse cytotoxic insults, for example, ROS and cytotoxic agents[33]. In current study, the CPD-2 suppressed the up-regulation of $\mathrm{Bax} / \mathrm{Bcl}-2$ ratio, and prevented $\mathrm{BaP}$-induced cytochrome $\mathrm{C}$ over-release. At the same time, CPD-2 also inhibited the activation of APAF-1. This partly explains the underlying mechanism of CPD-2 against the BaP-induced Caco-2 cells apoptosis.

$\mathrm{BaP}$, released from various industrial activities, is first oxidized by CYP1A1 to phenols[26]. CYP1A1 is one of the most important human P450 enzymes involved in the metabolic activation of PAHs. AhR is a transcription factor that is critical in xenobiotic metabolis[27]. In current study, we provided evidence that AhR is a key molecular regulator for BaP-induced the inflammatory epithelial cytokines over-expression. In particular, we found that BaP-induced the activation of AhR signaling as determined by expression of AhR and CYP1A1. Intriguingly, the increased expression was significantly inhibited by impaired in cells with AhR knockdown or CPD-2 treatments. These data indicate that AhR signal pathway is also essential in attenuating BaP-induced inflammatory epithelial cytokines expression in Caco-2 cells.

\section{Declarations}

\section{Ethics approval and consent to participate}

Not applicable.

\section{Consent for publication}

Not applicable.

\section{Availability of data and materials}

Not applicable.

\section{Competing interests}

The authors certify that there is no conflict of interest with any individual/organization for the present work. All the data was available and was got by our own experiments.

\section{Funding}


This work is supported by research grants from the Basic and applied basic research fund of Guangdong Province: 2019A1515110101; 2019A1515110010 and Youth Science Foundation Project: 82003464. This work is also supported by grant from the Shenzhen Kexing Pharmaceutical Co., Ltd.

\section{Authors' contributions}

Jie Liu conceived and designed the study. Zhuwei Liang and Huailing Wang performed the experiments and wrote the draft. Dan Luo collect the sample. Xiaoyu Liu analyzed the data. Jie Liu and Xiaoyu Liu revised the manuscript. All authors read and approved the manuscript.

\section{Acknowledgements}

Not applicable.

\section{Authors' information}

${ }^{1}$ State Key Laboratory of Respiratory Disease for Allergy at Shenzhen University, Shenzhen Key Laboratory of Allergy \& Immunology, Shenzhen University School of Medicine, Shenzhen, 518060, China.

${ }^{2}$ Clinical laboratory, Guangzhou Women and Children's Medical Center, Guangzhou Medical University, Guangzhou, 510623, China.

${ }^{3}$ Department of Allergy, The Third Affiliated Hospital of Shenzhen University, Shenzhen, 518020, China.

\section{References}

1. Mario M-T et al (2018) Polycyclic Aromatic Hydrocarbons (PAHs) Associated with PM2.5 in Guadalajara, Mexico: Environmental Levels, Health Risks and Possible Sources. Environments 5(5):62

2. Dimitriou K, Kassomenos $P$ (2017) The influence of specific atmospheric circulation types on PM 10 -bound benzo(a)pyrene inhalation related lung cancer risk in Barcelona. Spain Environment International 112:107

3. Suzuki Y et al (2009) Discrete generations of intracellular hydrogen peroxide and superoxide in antigen-stimulated mast cells: reciprocal regulation of store-operated $\mathrm{Ca} 2+$ channel activity. $\mathrm{Mol}$ Immunol 46(11):2200-2209

4. Im AK et al (2017) Induction of apoptosis by ethanol extract of Citrus unshiu Markovich peel in human bladder cancer T24 cells through ROS-mediated inactivation of the PI3K/Akt pathway. Biosci Trends 11(5):565-573 
5. Spriano D, Meier B (2011) Contents of ephedrine-like alkaloid synephrine in traditional Chinese decoctions.Planta Medica, 77(12)

6. Li YM et al (2008) Vivo Pharmacokinetics of Hesperidin Are Affected by Treatment with Glucosidaselike BglA Protein Isolated from Yeasts. Journal of Agricultural \& Food Chemistry 56(14):5550-7

7. Xu GH et al (2010) Minerals, Phenolic Compounds, and Antioxidant Capacity of Citrus Peel Extract by Hot Water. J Food Sci 73(1):C11-C18

8. Choi MY et al (2011) Effects of storage period and heat treatment on phenolic compound composition in dried Citrus peels (Chenpi) and discrimination of Chenpi with different storage periods through targeted metabolomic study using HPLC-DAD analysis. Journal of Pharmaceutical \& Biomedical Analysis 54(4):638-645

9. Miyata $Y$ et al (2011) Regulation of adipocytokine secretion and adipocyte hypertrophy by polymethoxyflavonoids, nobiletin and tangeretin. Life Sci 88(13-14):0-618

10. Lin N et al (2003) Novel anti-inflammatory actions of nobiletin, a citrus polymethoxy flavonoid, on human synovial fibroblasts and mouse macrophages. Biochem Pharmacol 65(12):2065-2071

11. Xu JJ et al (2014) Antiviral Activity of Polymethoxylated Flavones from "Guangchenpi", the Edible and Medicinal Pericarps of Citrus reticulata 'Chachi'. J Agric Food Chem 62(10):2182-2189

12. Wei $L$ et al (2012) Pressurised liquid extraction combining LC-DAD-ESI/MS analysis as an alternative method to extract three major flavones in Citrus reticulata 'Chachi' (Guangchenpi). Food Chem 130(4):1044-1049

13. Liu D et al (2011) Inhibition of autophagy by 3-MA potentiates cisplatin-induced apoptosis in esophageal squamous cell carcinoma cells. Med Oncol 28(1):105-111

14. Ling $Y$ et al (2009) Endostar Induces Apoptotic Effects in HUVECs through Activation of Caspase-3 and Decrease of Bcl-2. Anticancer Res 29(1):411-417

15. González A et al (2020) Benzopyrene induces oxidative stress and increases expression and activities of antioxidant enzymes, and CYP450 and GST metabolizing enzymes in Ulva lactuca (Chlorophyta). Planta 252(6):1-13

16. Zahran EM et al (2014) Polymeric plasticizer extends the lifetime of PVC-membrane ion-selective electrodes. Analyst 139(4):757-763

17. Piotr et al (2014) The role of inflammatory and anti-inflammatory cytokines in the pathogenesis of osteoarthritis. Mediators of Inflammation

18. Erkekoglu P et al (2012) The effects of di(2-ethylhexyl)phthalate exposure and selenium nutrition on sertoli cell vimentin structure and germ-cell apoptosis in rat testis. Arch Environ Contam Toxicol 62(3):539-547

19. Rabinovitch A et al (1999) Transfection of human pancreatic islets with an anti-apoptotic gene (bcl2) protects beta-cells from cytokine-induced destruction. Diabetes 48(6):1223

20. Haraguchi M et al (2000) Apoptotic Protease Activating Factor 1 (Apaf-1)-Independent Cell Death Suppression by Bcl-2. J Exp Med 191(10):1709-1720 
21. Guo H, Callaway JB, Ting PY (2015) Inflammasomes: mechanism of action, role in disease, and therapeutics. Nat Med 21(7):677-687

22. Xie Q et al (2014) Lipopolysaccharide/adenosine triphosphate induces IL $1 \beta$ and IL-18 secretion through the NLRP3 inflammasome in RAW264.7 murine macrophage cells. International Journal of Molecular Medicine,

23. Yao ST et al (2017) NLRP3 is Required for Complement-Mediated Caspase-1 and IL-1beta Activation in ICH.Journal of Molecular Neuroscience,

24. Vondrá?Ek J et al (2009) The role of aryl hydrocarbon receptor in regulation of enzymes involved in metabolic activation of polycyclic aromatic hydrocarbons in a model of rat liver progenitor cells. Chemico-Biol Interact 180(2):226-237

25. Alvarez-Gonzalez I et al (2011) The antigenotoxic effects of grapefruit juice on the damage induced by benzo(a)pyrene and evaluation of its interaction with hepatic and intestinal Cytochrome P450 (Cур)1a1. Food \& Chemical Toxicology, 49(4): p. 807-811

26. Kobayashi S et al (2013) Genetic association of aromatic hydrocarbon receptor (AHR) and cytochrome P450, family 1, subfamily A, polypeptide 1 (CYP1A1) polymorphisms with dioxin blood concentrations among pregnant Japanese women. Toxicol Lett 219(3):269-278

27. Shi H, Liu J, Gao H Benzo(a)pyrene induces oxidative stress and inflammation in human vascular endothelial cells through AhR and NF-KB pathways. Microvascular Research, 2021(1): p. 104179

28. Kasab SA et al (2018) Intracranial Large and Medium Artery Atherosclerotic Disease and Stroke.J Stroke Cerebrovasc Dis, : p.S1052305718301125

29. Mario MT et al (2018) Polycyclic Aromatic Hydrocarbons (PAHs) Associated with PM2.5 in Guadalajara, Mexico: Environmental Levels, Health Risks and Possible Sources. Environments 5(5):62

30. Endothelial dysfunction in aged humans is related with oxidative stress and vascular inflammation.Aging Cell, 8

31. Balachandar R, Barron RM (2014) Reply to Discussion by Duarte of "CFD analysis of the effect of nozzle stand-off distance on turbulent impinging jets".Canadian Journal of Civil Engineering,

32. Tekippe ME et al (2010) Granuloma Formation and Host Defense in Chronic Mycobacterium tuberculosis Infection Requires PYCARD/ASC but Not NLRP3 or Caspase-1. PLoS ONE 5(8):e12320

33. Rabinovitch et al (1999) Transfection of human pancreatic islets with an anti-apoptotic gene (bcl-2) protects beta-cells from cytokine-induced destruction.Diabetes,

\section{Figures}


<smiles>COC(=O)C(Cc1ccccc1)NC(=O)C(C)C(NC(=O)c1cc(OC)c(OC)c(OC)c1)C(=O)NC(Cc1ccccc1)C(=O)OC</smiles>

CPD-1

CPD-2

CPD-3<smiles>CCC(C)C(NC(=O)C(NC(=O)c1cc(OC)c(OCOC(=O)C(NC(=O)C(NC(=O)c2cc(OC)c(OC)c(OC)c2)C(C)C)C(C)C)c(OC)c1)C(C)C)C(=O)OC</smiles>

CPD-4

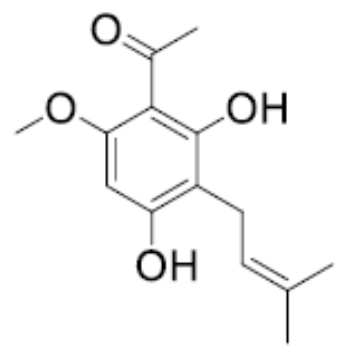

CPD-8
CPD-5<smiles>CCCC(=O)c1c(O)cc(OC)c(CC2=C(O)C(C)(C)C(O)=C(C(=O)C(C)C)C2=O)c1O</smiles>

CPD-9<smiles>CC=CCc1c(O)c(C(C)=O)c(OC)c(C(CC(C)C)OC)c1O</smiles>

CPD-6<smiles>CCCC(=O)c1c(O)cc(OC)c(CC2=C(O)C(C)(C)C(O)=C(C(=O)O)C2=O)c1O</smiles>

CPD-10

Figure 1

Structures of CPD-1 10 
A
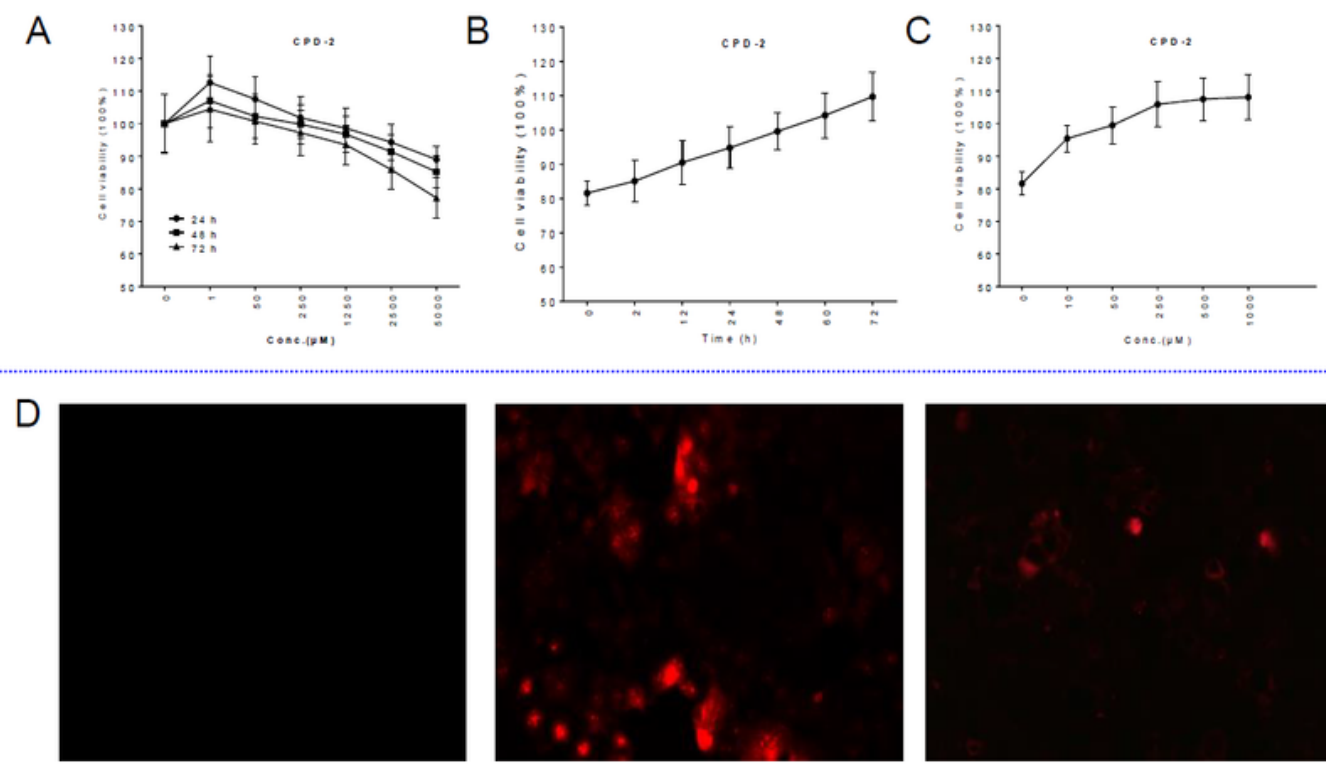

Control
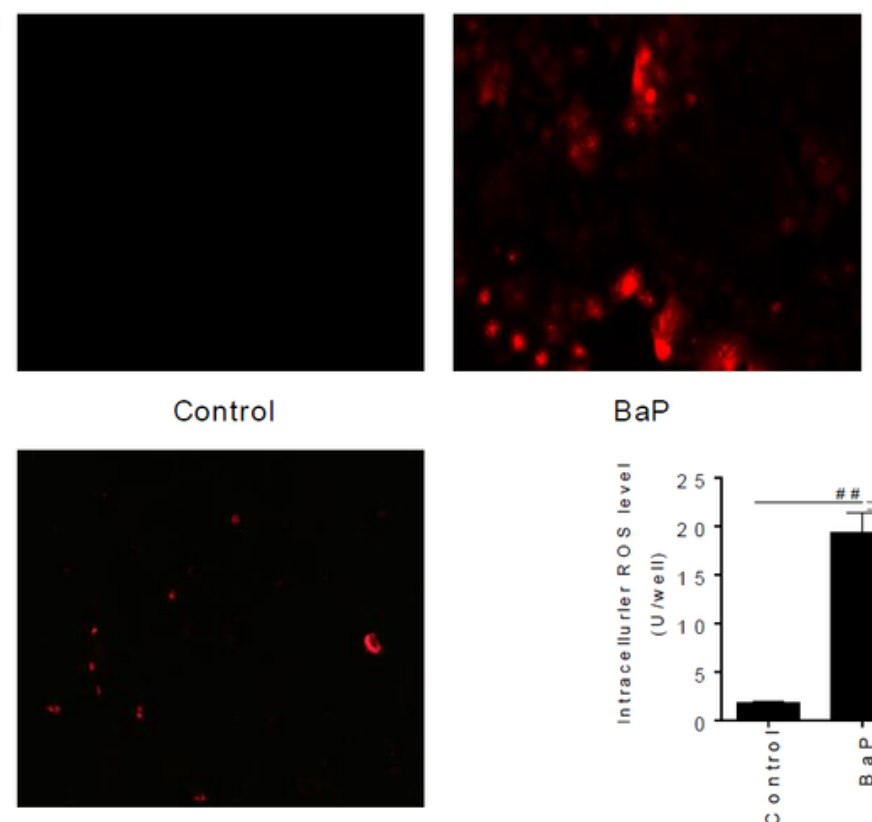

$\mathrm{BaP}$

$10 \mu \mathrm{M}$
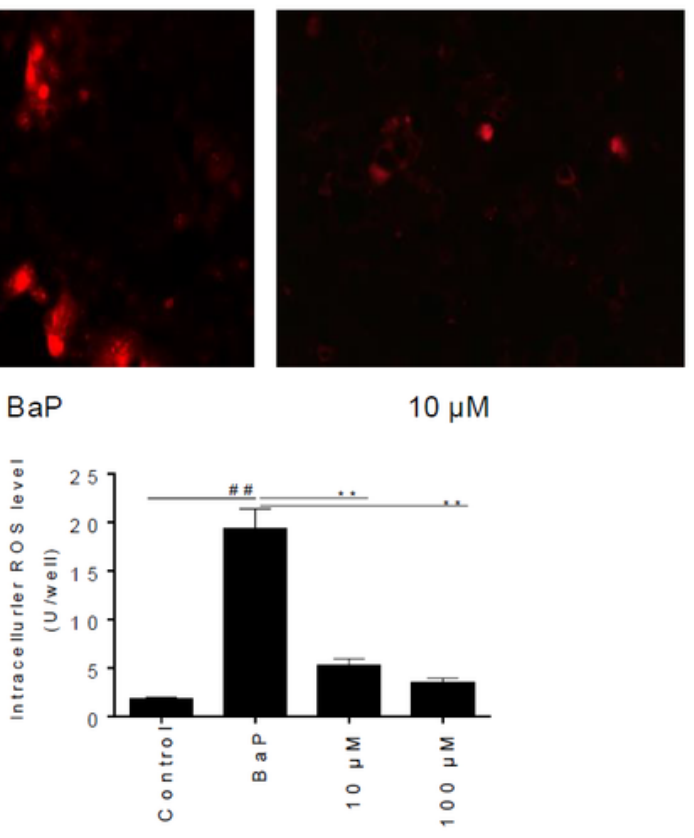

$100 \mu \mathrm{M}$

E
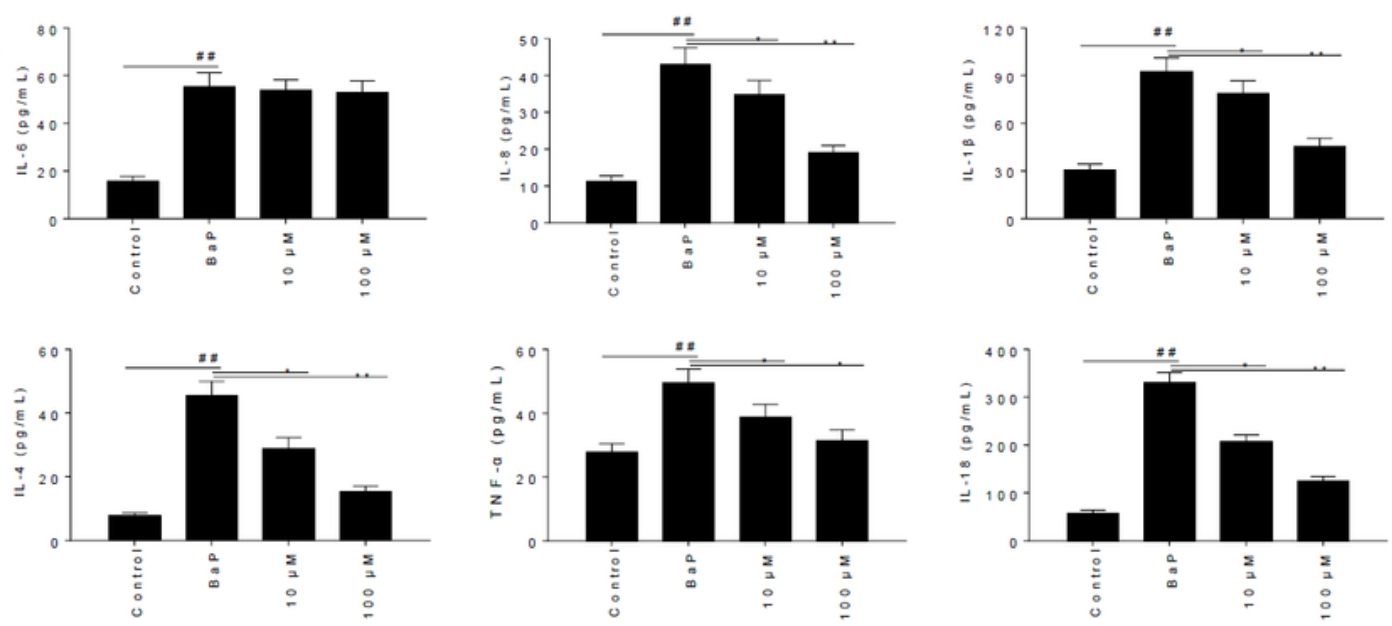

\section{Figure 2}

CPD-2 inhibits BaP-induced intracellular ROS over-production and inflammatory cytokines overexpression of Caco-2 cells (A) Cytotoxicity of CPD-2 in Caco-2 cells; (B, C) CPD-2 attenuates BaP-induced viability decline of Caco-2 cells in a dose-and time-dependent manner. The cell viability of the Caco-2 cells was evaluated using CCK-8 assay method; (D) Detection of intracellular ROS production with Reactive Oxygen Species Assay Kit. The dihydrodichlorofluorescein diacetate (DCF-DA) fluorescence was 
quantitated with a Multiskan Go plate reader and normalized with the total protein content; (E) Detection of inflammatory cytokine levels of Caco-2 cells. Levels of IL-4, IL-6, IL-8, TNF-a, IL-1 $\beta$ and IL-18 in culture supernatants were detected by ELISA $(n=3)$. Data are presented as means $\pm \operatorname{SEM}(n=3)$. ${ }^{\star *} p<0.01,{ }^{*} p<$ 0.05 compared to the BaP group; \#p $<0.05$, \#\#p $<0.01$ compared to the Control group.

A

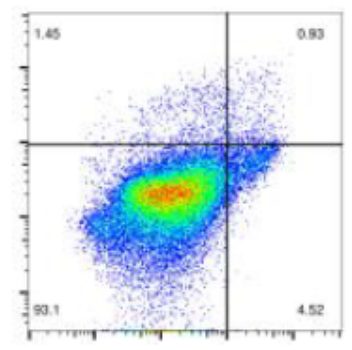

Control

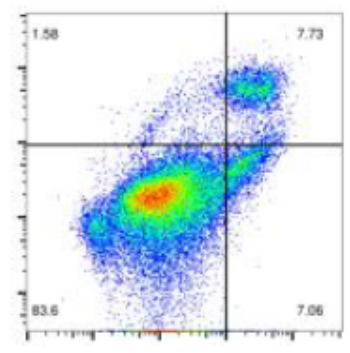

$100 \mu \mathrm{M}$

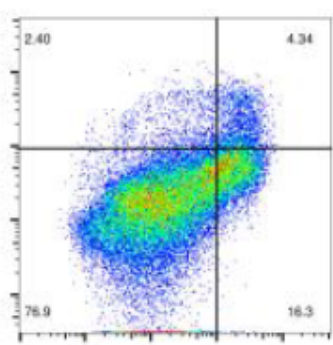

$\mathrm{BaP}$

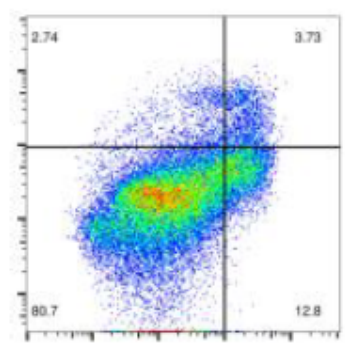

$10 \mu \mathrm{M}$

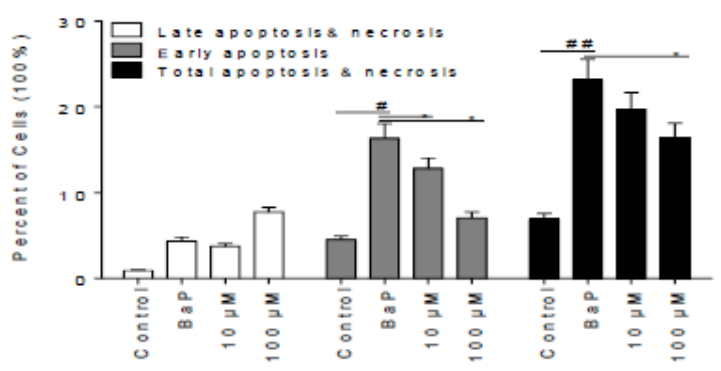

B

Bax
Bcl-2
Cytoplasmic cyt C
Nuclear cyt C
APAF-1
$\beta$-actin
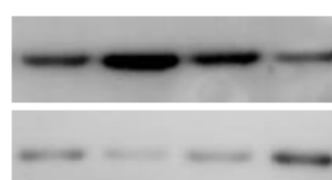

\section{-}

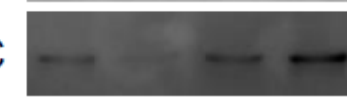

\section{.}
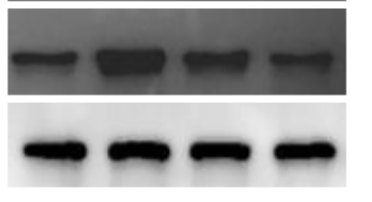

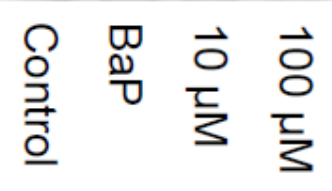

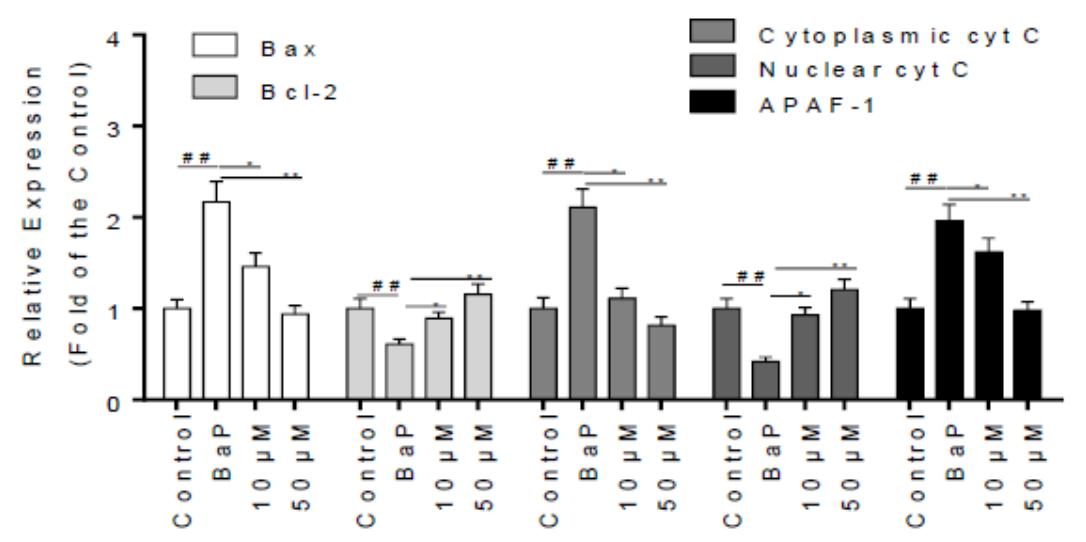

\section{Figure 3}

CPD-2 inhibits BaP-induced apoptosis of Caco-2 cells (A) Apoptosis detection of Caco-2 cells under BaPexposure with or without CPD-2 treatment. After the Caco-2 cells were treated as the experimental design, the cells were collected, stained with Annexin- $\mathrm{V}$ and $\mathrm{PI}$, and were evaluated by the flow cytometry. The lower left quadrant shows the viable cells, the upper left shows necrotic cells, the lower right shows the early apoptotic cells; while the upper right shows late apoptotic cells. In each scatter diagrams, the abscissa represents the fluorescence intensity of the cells dyed by Annexin V; and the ordinate represents the fluorescence intensity of the cells dyed by PI. (B) The expression of proteins related to apoptosis were 
evaluated by western blot analysis. Data are presented as means $\pm \operatorname{SEM}(n=3)$. ${ }^{* \star} p<0.01,{ }^{*} p<0.05$ compared to the BaP group; \#p $<0.05$, \#\#p $<0.01$ compared to the Control group.
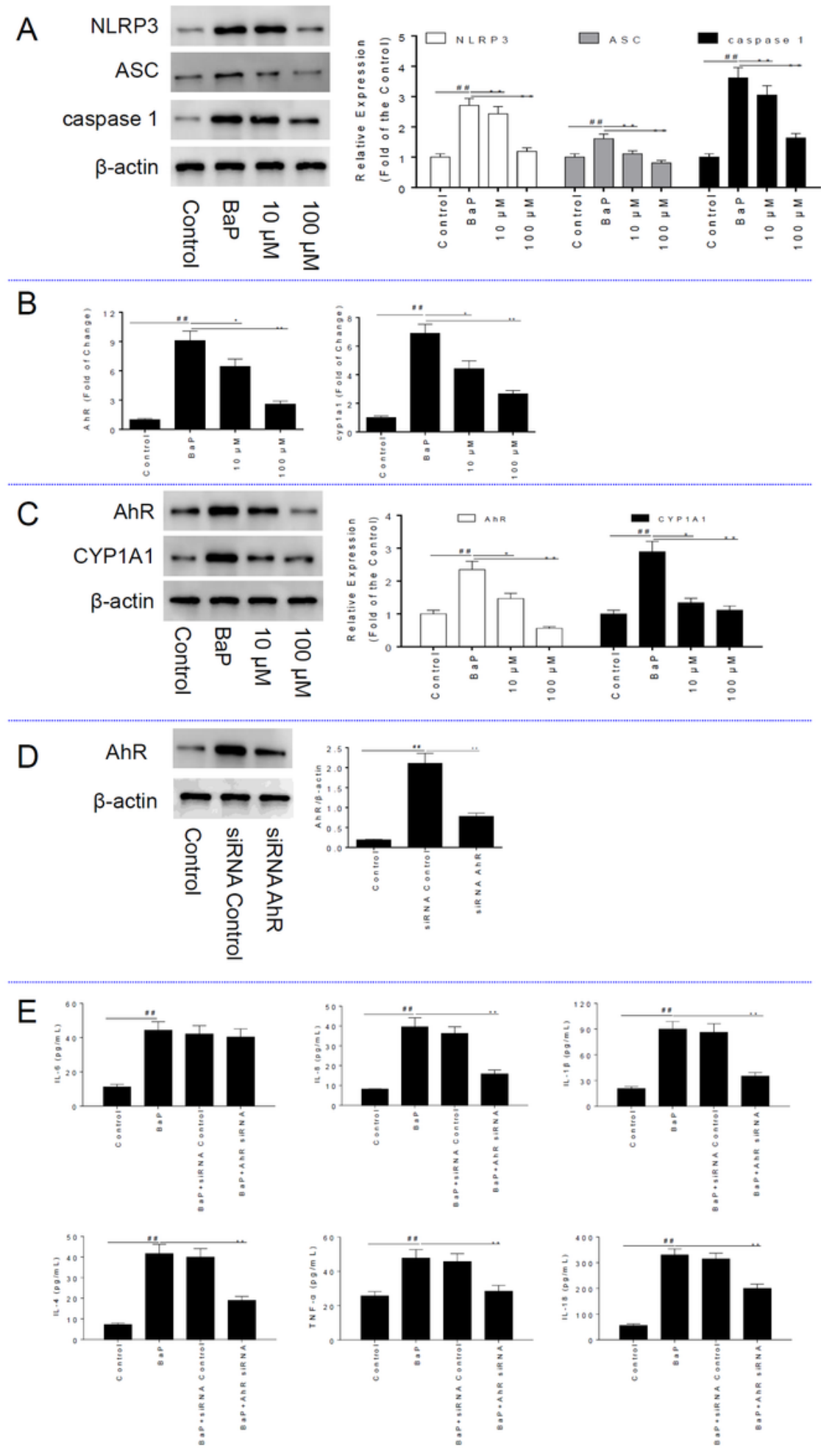

Figure 4

CPD-2 inhibited activation of BaP-induced NLRP3 inflammasome and AhR signaling in Caco-2 cells. (A) Proteins expression of NLRP3, ASC and caspase- 1 was evaluated by western blot analysis; (B) RT-PCR analysis for the transcription of AhR and cyp1a1 in BaP-induced Caco-2 cells with or without CPD-2 
treatments; (C) Proteins expression of AhR and CYP1A1 were evaluated by western blot analysis; (D) AhR knockdown was confirmed by western blotting; (E) ELISA analysis for the expression of inflammatory epithelial cytokines in BaP-induced Caco-2 cells with or without AhR knockdown. Data are presented as means \pm SEM. Each point represents at least three independent experiments. * or \# indicate statistically significant differences: ${ }^{\star \star} p<0.01,{ }^{*} p<0.05$ compared to the BaP group; $\# p<0.05, \# \# p<0.01$ compared to the Control group.

\section{Supplementary Files}

This is a list of supplementary files associated with this preprint. Click to download.

- GraphicalAbstract.png 